\title{
Determination of Five Phthalate Esters and Bisphenol A in Fruit Juice by Packed-nanofiber Solid Phase Extraction Coupled with Gas Chromatography
}

\author{
Zigang Tang ${ }^{1}$, Tao Kang ${ }^{2}$, Xuejun Kang ${ }^{1,3}$ * \\ 1. School of Public Health of Southeast University, Laboratory of Environment and Biosafety Research Institute \\ of Southeast University in Suzhou, Suzhou 215123, China \\ 2. Jiangsu Dongda Jinzhi Information System Co.LTD, Nanjing 211100, China \\ 3. Key Laboratory of Child Development and Learning Science (Ministry of Education), School of Biological \\ Sciences \& Medical Engineering, Southeast University, Nanjing 210096, China \\ E-mail: xjkang64@163.com (Corresponding author)
}

Received: 15 November 2018; Accepted: 29 November 2018; Available online: 1 May 2019

\begin{abstract}
Packed-nanofiber solid phase extraction (PFSPE) combined with gas chromatography-flame ionization detector (GC-FID) was developed for the simultaneous determination of five phthalate esters (PAEs) and bisphenol A (BPA) in fruit juice. The PAEs and BPA was concentrated by PFSPE using polystyrene- pyridine (PS-PD) nanofibers as the sorbent, followed determined by GC-FID. Under this modified procedure, satisfied recoveries in fruit juice sample ranging from $81.9 \%$ to $109.6 \%$ were obtained. And relative standard deviation values (RSD) were ranged from $1.9 \%$ to $9.8 \%$ in orange juice sample. The limits of detection (LOD) and the limits of quantification (LOQ) of five PAEs and BPA were ranged from $0.02 \mu \mathrm{g} / \mathrm{mL}$ to $0.30 \mu \mathrm{g} / \mathrm{mL}$ and $0.06 \mu \mathrm{g} / \mathrm{L}$ to 1.10 $\mu \mathrm{g} / \mathrm{L}$, respectively. This established method was successfully applied to detect real fruit juice samples, which were collected in local supermarket. These results demonstrated the applicability of the established PFSPE-based extraction coupled with gas chromatography method for determination of PAEs and BPA in fruit juice products.

Keywords: Packed-nanofiber solid phase extraction(PFSPE); Phthalate esters (PAEs); Bisphenol A (BPA); Gas chromatography-flame ionization detector (GC-FID); Fruit juice.
\end{abstract}

\section{Introduction}

During the past decades, phthalate esters (PAEs) and bisphenol A (BPA) were widely spread and used as a plasticizer in global world, which are proved to be great threats to human lives and health even at low concentrations [1]. PAEs and BPA were easy stored in the surface water and entered into the food chain, after degradation, then moved into the food, such as bottled water and orange juice [1,2]. And as disruptor chemicals (EDC) and weak environmental estrogens, a tiny amount of residue could damage to endocrine system of the organism [1]. They are also easily be released and migrated from food packages and beverage packaging materials to food and beverage [3-5].

The most classic extraction methods of PAEs and BPA was soxhlet extraction, but it could only be used in laboratory with high energy consumption [6]. Conventional pretreatment methods have been emerged for the extraction of PAEs and BPA in sample pretreatment process such as solid-phase extraction (SPE) [7], liquid-liquid extraction (LLE) [8], microwave extraction [9] and so on. However, most of them are time consuming, and require a large amount of sorbents and organic solvents [10]. Therefore, the above methods were difficult to meet the requirements to determination of PAEs and BPA in complex matrix, which makes it urgent to establish a simple and sensitive analytical method for monitoring the content of PAEs and BPA in fruit juice.

Recently, a novel SPE method based on electrospun polymer nanofibers as adsorbent for the preconcentration of the target compounds was developed [11]. Owing to the large surface area of the nanofiber, which facilitates the attachment of target molecules and the miniaturization of SPE device, the extraction capability of packednanofiber solid-phase extraction (PFSPE) could be efficiently improved. In addition, the amounts of sample and the volume of desorption solvent could also be reduced.

In this study, a modified PFSPE procedure coupled with GC-FID method was established for the enrichment and determination of five PAEs and BPA in fruit juice matrix. The eluent and its volume were optimized. The performance of established analytical method for the determination of five PAEs and BPA residues in orange juice was evaluated. 


\section{Materials and methods.}

\subsection{Chemicals and materials}

Polystyrene (PS), pyridine (PD) were from Shanghai Chemical Agents Institute (Shanghai, China). GC-grade benzyl butyl phathalate (BBP), diethyl-o-phthalate (DEP), dibutyl-o-phthalate (DBP), di (2-ethylhexyl) phathalate (DEHP), di-n-octyl phthalate (DNOP), and n-Hexane (HPLC-grade) were obtained from Aladdin reagent (Shanghai, China). Bisphenol A (CP) was purchased from Nanjing Chemical Reagent Co., LTD (Nanjing, china), and acetone (AR-grade) was purchased from Sinopharm chemical Reagent Co., LTD (Shanghai, China). Perchlorate acid (GR) was from Shanghai golden deer chemical Co., LTD (Shanghai, China), methanol (HPLCgrade) and acetonitrile (ACN) were purchased from Yuwang group (Dezhou, China). Ethanol (HPLC-grade) was purchased from Kemiou Chemical Reagent Co (Tianjin, china). Bottled orange juice samples were purchased from local supermarkets (Nanjing, China). Standard stocking solutions of PAEs and BPA were prepared in ACN at 100 $\mu \mathrm{g} / \mathrm{mL}$.

\subsection{Sample preparation}

The fruit juice samples were collected from located supermarkets, and stored in carton at $4^{\circ} \mathrm{C}$ until analysis. The fruit samples centrifuged for 5 min at 10,000 rpm, then the supernate was applied to PFSPE experiment.

\subsection{Packed-nanofiber solid phase extraction}

Before use, the polystyrene/pyridine composite (PS/PD) nanofibers should be activated. The columns were preconditioned by eluting with $200 \mu \mathrm{L}$ methanol followed by $400 \mu \mathrm{L}$ of deionized water. After that, the nanofibers were ready for sample pretreatment. Five hundred microliters of sample solution were transferred to the cartridge and pushed through the pre-conditioned PS/PD nanofibers by air pressure forced using a gas-tight syringe $(10 \mathrm{~mL})$, which was fitted to the top of the extraction cartridge. Then $100 \mu \mathrm{L}$ ACN was loaded onto the extraction column and pushed through it again. Finally, $1 \mu \mathrm{L}$ eluent was analyzed by GC-FID.

\subsection{Chromatographic procedures}

A GC-2010 gas chromatograph (Agilent, American) equipped with a GC- flame ionization detector (FID) and a split/splitless capillary column injector was used for the analysis. Separation was performed on a HP-5 (30 $\mathrm{cm} \times 0.32 \mathrm{~mm}$ i.d. $\times 0.25 \mu \mathrm{m}$ film thickness) capillary column. Nitrogen $\left(\mathrm{N}_{2}\right)$ was used as the carrier and makeup gas at a flow rate of $2.0 \mathrm{~mL} / \mathrm{min}$ (constant flow). The column oven temperature program was as follows: increased from $100^{\circ} \mathrm{C}$ (held for $2 \mathrm{~min}$ ) to $270^{\circ} \mathrm{C}$ with the rate of $15^{\circ} \mathrm{C} / \mathrm{min}$ and maintained for $5 \mathrm{~min}$. The FID temperature was set at $270^{\circ} \mathrm{C}$. The standard solutions and sample extracts $(1.0 \mu \mathrm{L})$ were injected using the splitless mode at an injection temperature of $250^{\circ} \mathrm{C}$.

\subsection{Quality assurance and quality control}

Quality assurance and quality control were verified to ensure the correct identification of PAEs and BPA in samples. In addition, the PAEs and BPA may exist in every corner laboratory environment. Therefore, the most of materials handled during the analytical procedure should be glass-made or plastic-free materials. And the methodblank sample was investigated, the blank sample run after every batch of 15 samples to control any systematic contamination.

\subsection{Method validation}

In order to insure the reliability of the established method, which validation parameters including linearity and accuracy, as well as limit of detection (LOD), limit of quantification (LOQ), precision of the method. The linearity was studied by designing seven concentrations of five PAEs and BPA at $0.01 \mu \mathrm{g} / \mathrm{mL}, 0.05 \mu \mathrm{g} / \mathrm{mL}, 0.1 \mu \mathrm{g} / \mathrm{mL}, 0.5$ $\mu \mathrm{g} / \mathrm{mL}, 1.0 \mu \mathrm{g} / \mathrm{mL}, 5.0 \mu \mathrm{g} / \mathrm{mL}, 10 \mu \mathrm{g} / \mathrm{mL}$. And the repeatability was verified to intra-day precision and inter-day precision (RSD) for continuously five days. For the established method, the LOD and LOQ were determined at signal-to-noise (S/N) ratios of 3:1 and 10:1, respectively. The precision of the method was validated by the relative standard deviation (RSD) using five parallel group.

\section{Results and discussion}

\subsection{Optimization of eluent}

The eluent plays an important role in PFSPE syetem. In this work, five kinds of solvents were investigated in order to elute the analytes from the nanofibers. The Fig.1 demonstrated that the satisfied extraction recoveries and RSDs were achieved with ACN. Hence, the ACN was chosen as the optimum desorption solvent for the further experiments. 


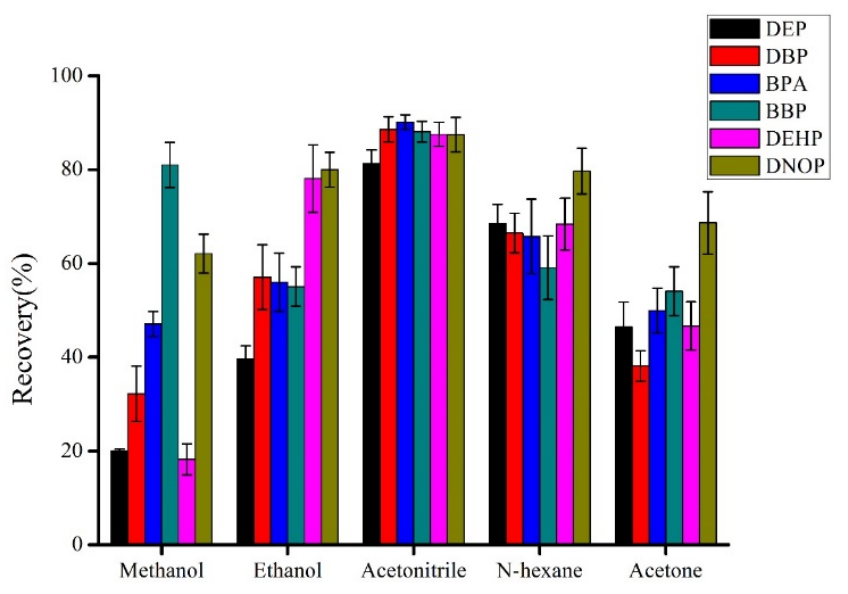

Fig.1 Effect of the eluent on the recovery

\subsection{Optimization of the volume of the eluent}

To ensure maximum elution efficiency of PAEs and BPA from the PFSPE columns, the volumes of ACN ranging from 50 to $150 \mu \mathrm{L}$ were tested for the optimal desorption of five PAEs and BPA from the whole nanofibers. Results shown in Fig. 2 clearly indicated that the extraction efficiency reached the highest point when the volume of the eluent was $100 \mu \mathrm{L}$, and the recoveries of five PAEs and BPA were almost not changed between 100 and $150 \mu \mathrm{L}$. Therefore, $100 \mu \mathrm{L}$ of ACN was selected as eluent in next extractions.

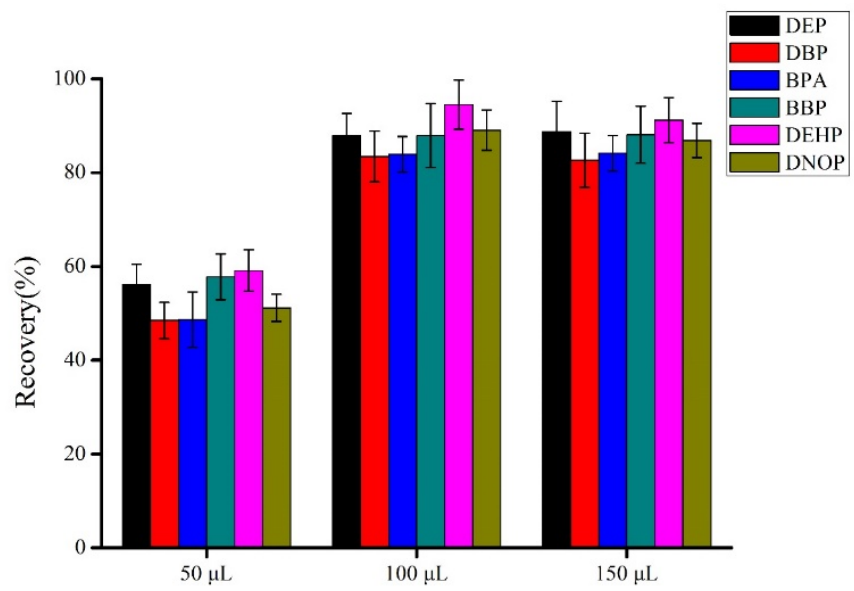

Fig.2 Effect of the eluent volume

\subsection{Analytical method validation}

The linearity of this modified PFSPE-based method for fruit juice was in the range of $0.01-10 \mu \mathrm{g} / \mathrm{mL}$. Selectivity was identified by injecting blank matrix solvent and spiked sample with five PAEs and BPA into the GC chromatograph for FID detection. The typical GC-FID chromatograms in Fig. 3 showed that the five PAEs and BPA were well separated and no obvious interfering peaks were observed, suggesting excellent selectivity of this method.

Reproducibility of the established method was studied based on the intra-day and inter-day precision. The intraday and inter-day precision was checked by injecting fruit sample spiked with five PAEs and BPA at three different concentrations $(0.1 \mu \mathrm{g} / \mathrm{mL}, 2 \mu \mathrm{g} / \mathrm{mL}, 5 \mu \mathrm{g} / \mathrm{mL})$ under optimum condition in consecutive five days with five groups per day. The tests were performed using the same independent preparation. As shown in table.1, good results were expressed in terms of relative standard deviations (RSDs) ranging from $1.9 \%$ to $9.8 \%$ in fruit juice sample. This result demonstrated the good reproducibility of the method and proved the effectiveness of the method for quantitative purposes. The LOD $(\mathrm{S} / \mathrm{N}=3.0)$ and LOQ $(\mathrm{S} / \mathrm{N}=10)$ of modified PFSPE method for five PAEs and BPA were ranged from $0.02 \mu \mathrm{g} / \mathrm{mL}$ to $0.3 \mu \mathrm{g} / \mathrm{mL}$ and $0.06 \mu \mathrm{g} / \mathrm{mL}$ to $0.19 \mu \mathrm{g} / \mathrm{mL}$, respectively. The results demonstrated the good sensitivity of the modified PFSPE method for monitoring PAEs and BPA in fruit juice samples. 


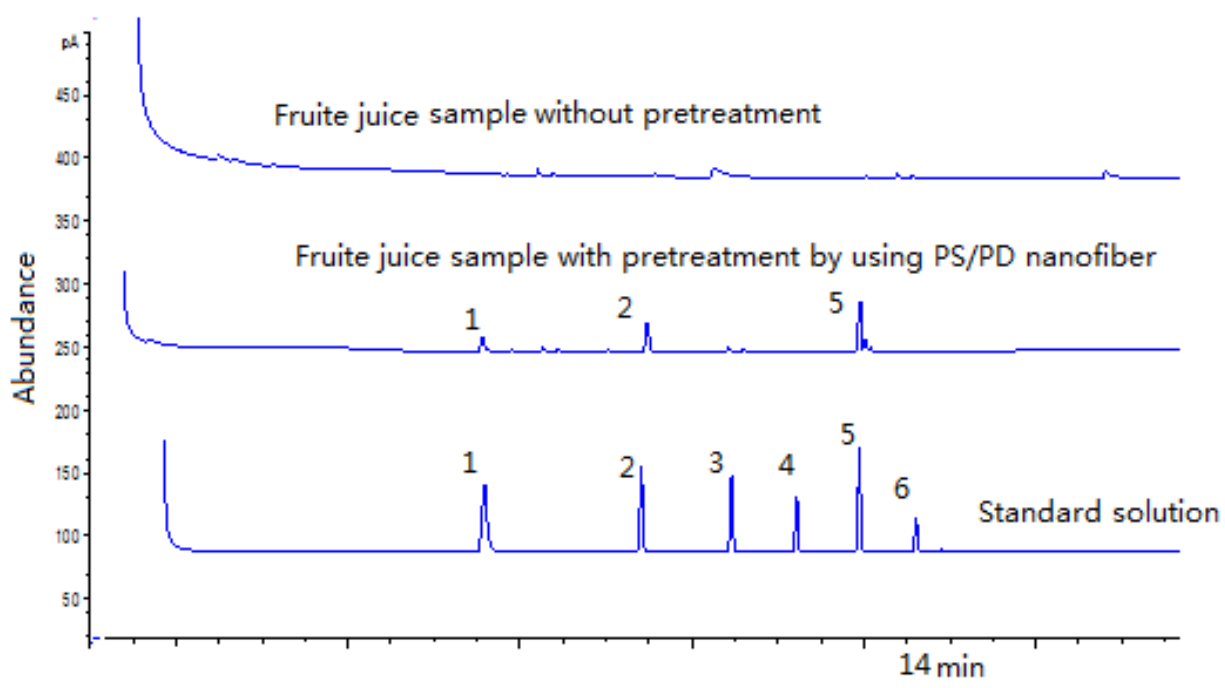

Fig.3 GC-FID chromatograms of $1 \mu \mathrm{g} / \mathrm{mL}$ of five PAEs and BPA standard in methanol (standard solution), fruit juice sample pretreated with and without PFSPE. (1) DEP; (2) DBP; (3) BPA; (4) BBP; (5) DEHP; (6) DNOP.

Table 1. Performance of GC-FID/PFSPE method in orange juice samples

\begin{tabular}{|c|c|c|c|c|c|c|c|c|c|}
\hline \multirow[t]{3}{*}{ Analytes } & \multirow{3}{*}{$\begin{array}{l}\text { Linear } \\
\text { range } \\
(\mu g / m L)\end{array}$} & \multicolumn{6}{|c|}{ Recovery $( \pm$ RSD \%) n=5, Spiked concentration $(\mu \mathrm{g} / \mathrm{mL})$} & \multirow{3}{*}{$\begin{array}{l}\text { LOD } \\
(\mu g / m L)\end{array}$} & \multirow{3}{*}{$\begin{array}{l}\mathrm{LOQ} \\
(\mu \mathrm{g} / \mathrm{mL})\end{array}$} \\
\hline & & \multicolumn{3}{|c|}{ Intraday } & \multicolumn{3}{|c|}{ Interday } & & \\
\hline & & 1 & 5 & 10 & 1 & 5 & 10 & & \\
\hline DEP & $0.01-10$ & $\begin{array}{l}90.4 \\
(2.8)\end{array}$ & $\begin{array}{l}88.7 \\
(3.1)\end{array}$ & $\begin{array}{l}83.0 \\
(2.9)\end{array}$ & $\begin{array}{l}88.6 \\
(2.3)\end{array}$ & $\begin{array}{l}97.5 \\
(4.2)\end{array}$ & $\begin{array}{l}93.6 \\
(7.5)\end{array}$ & 0.02 & 0.06 \\
\hline DBP & $0.01-10$ & $\begin{array}{l}103.9 \\
(6.7)\end{array}$ & $\begin{array}{l}108.2 \\
(8.7)\end{array}$ & $\begin{array}{l}106.3 \\
(2.9)\end{array}$ & $\begin{array}{l}109.6 \\
(2.9)\end{array}$ & $\begin{array}{l}81.9 \\
(2.9)\end{array}$ & $\begin{array}{l}90.3 \\
(8.6)\end{array}$ & 0.04 & 0.13 \\
\hline BPA & $0.01-10$ & $\begin{array}{l}96.0 \\
(4.9)\end{array}$ & $\begin{array}{l}94.0 \\
(3.9)\end{array}$ & $\begin{array}{l}94.7 \\
(6.6)\end{array}$ & $\begin{array}{l}107.0 \\
(3.9)\end{array}$ & $\begin{array}{l}88.0 \\
(2.3)\end{array}$ & $\begin{array}{l}89.5 \\
(3.6)\end{array}$ & 0.03 & 0.10 \\
\hline BBP & $0.01-10$ & $\begin{array}{l}94.3 \\
(4.9)\end{array}$ & $\begin{array}{l}96.8 \\
(4.9)\end{array}$ & $\begin{array}{l}97.6 \\
(2.3)\end{array}$ & $\begin{array}{l}90.5 \\
(7.6)\end{array}$ & $\begin{array}{l}105.8 \\
(4.8)\end{array}$ & $\begin{array}{l}90.7 \\
(4.6)\end{array}$ & 0.06 & 0.19 \\
\hline DEHP & $0.01-10$ & $\begin{array}{l}89.8 \\
(3.9)\end{array}$ & $\begin{array}{l}89.4 \\
(4.3)\end{array}$ & $\begin{array}{l}101.7 \\
(1.9)\end{array}$ & $\begin{array}{l}91.3 \\
(2.3)\end{array}$ & $\begin{array}{l}104.4 \\
(9.8)\end{array}$ & $\begin{array}{l}101.0 \\
(4.8)\end{array}$ & 0.30 & 1.1 \\
\hline DNOP & $0.01-10$ & $\begin{array}{l}106.9 \\
(4.1)\end{array}$ & $\begin{array}{l}91.5 \\
(2.4) \\
\end{array}$ & $\begin{array}{r}108.0 \\
(5.1) \\
\end{array}$ & $\begin{array}{l}86.2 \\
(2.6) \\
\end{array}$ & $\begin{array}{l}115.0 \\
(6.6)\end{array}$ & $\begin{array}{l}103.3 \\
(7.9)\end{array}$ & 0.05 & 0.17 \\
\hline
\end{tabular}

\subsection{Application of the developed procedure to real samples}

The practical applicability of this PFSPE/GC-FID method was evaluated with real fruit juice samples under the optimized conditions. The chromatograms of the sample and the standard were shown in Fig.3. Without the pretreatment by the PFSPE, the response value of five PAEs and BPA could not be detected because of the interference of other components in the fruit juice sample. But after pretreatment, the response value of PAEs and BPA was obviously increased and the interference was efficaciously weakened. Moreover, the novel method was successfully applied to the determination of trace five PAEs and BPA in the sample of three kinds of fruit juice samples, the results were shown in the Table. 2. The DEHP and DBP were all detected in fruit juice samples could be due to their wide use in packaging material.

\section{Conclusion}

With the advantage of PFSPE-based extraction system, we established a rapid and convenient method to determine five PAEs and BPA in fruit juice samples. All parameters that affecting the extraction efficiency of PFSPE-based extraction system for enrichment and determination of PAEs and BPA were optimized. Under the optimal conditions, the satisfied recoveries in the range of $81.9 \%$ to $109.6 \%$ were obtained. This method could provide technical support for monitoring PAEs and BPA in fruit juice from the coastal supermarket. The results demonstrated the PFSPE/GC-FID method we established was successfully applied to the determination of PAEs 
and BPA in fruit juice products.

Tab. 2 The presence of PAEs and BPA in three kinds of fruit juice samples by this developed method

\begin{tabular}{llll}
\hline Componds & \multicolumn{3}{c}{ Concentration $(\mu \mathrm{g} / \mathrm{mL})$} \\
\cline { 2 - 4 } & Sample 1 & Sample 2 & Sample 3 \\
\hline DEP & 0.029 & & 0.033 \\
DBP & 0.310 & 0.340 & 0.290 \\
BPA & & & \\
BBP & & & 0.704 \\
DEHP & 0.601 & 0.502 & \\
DNOP & & & \\
\hline
\end{tabular}

\section{Acknowledgements}

This study was supported by the National Natural Science Foundation of China (Grant No. 81673230, and No. 21307086), and the Social Development Research Program of Jiangsu Province Science and Technology department (No. BE2016741).

\section{References}

[1] Gu, Y., Yu, X., Peng, J., Chen, S., Zhong, Y., Yin, D., Hu, X. Simultaneous solid phase extraction coupled with liquid chromatography tandem mass spectrometry and gas chromatography tandem mass spectrometry for the highly sensitive determination of 15 endocrine disrupting chemicals in seafood. J. Chromatogr. B. 2014; 965: 164-172.

[2] Wu, S., Xu, Q., Chen, T., Wang, M., Yin, X., Zhang, N., Shen, Y., Wen, Z., Gu, Z. Determination of bisphenol A in plastic bottled drinking water by high performance liquid chromatography with solid-phase extraction based on electrospun nylon 6 nanfiberbrous membrane. Chinese. J. Anal. Chem. 2010; 38 (4): 503-507.

[3] Al-Saleh, I., Elkhatib, R., Al-Rajoudi, T., Al-Qudaihi, G. Assessing the concentration of phthalate esters (PAEs) and bisphenol A (BPA) and the genotoxic potential of treated wastewater (final effluent) in Saudi Arabia. Sci. total. Environ. 2017; 578: 440-451.

[4] Singh, S., Li, S. S. Bisphenol A and phthalates exhibit similar toxicogenomics and health effects. Gene. 2012; 494: 85-91.

[5] S. vom Saal, F., V. Welshons, W. Evidence that bisphenol A (BPA) can be accurately measured without contamination in human serum and urine, and that BPA causes numerous hazards from multiple routes of exposure. Mol Cell Endocrinol. 2014; 398: 101-113.

[6] Tinne Geens, Laurence Roosens, Hugo Neels, Adrian Covaci. Assessment of human exposure to BisphenolA, Triclosan and Tetrabromobisphenol-A through indoor dust intake in Belgium. Chemosphere. 2009;76: 755-760.

[7] Singh, S., Li, S. S. Bisphenol A and phthalates exhibit similar toxicogenomics and health effects. Gene. 2012; 494: 85-91.

[8] Diana, A., Dimitra, V. Alkylphenols and phthalates in bottled waters. J Hazard. Mater. 2011; 185: 281-286.

[9] Bartolome, L., Cortazar, E., Raposo, J. C., Raposo, Usobiaga, A., Zuloaga O., Etxebarria, N., Ferneandez, L. A. Simultaneous microwave-assisted extraction of polycyclic aromatic hydrocarbons, polychlorinated biphenyls, phthalate esters and nonylphenols in sediments. J. Chromatogr. A. 2005; 1068: 229-236.

[10] Farajzadeh, M. A., Djozan, D., Afshar, M. R., Mogaddam., Norouzi, J. Determination of phthalate esters in cow milk samples using dispersive liquid- liquid microextraction coupled with gas chromatography followed by flame ionization and mass spectrometric detection. J. Sep. Sci. 2012; 35: 154-162.

[11] Kang, X., Pan, C., Xu, Q., Yao, Y., Wang, Y., Qi, D., Gu, Z. The investigation of electrospun polymer nanofibers as a solid-phase extraction sorbent for the determination of trazodone in human plasma. Anal. Chim. Acta. 2 (1): 75-81.

(C) 2019 by the author(s). This work is licensed under a Creative Commons Attribution 4.0 International License (http://creativecommons.org/licenses/by/4.0/). Authors retain copyright of their work, with first publication rights granted to Tech Reviews Ltd. 